\title{
ARTICLE \\ Improvement of Scintillation Characteristics of FZ Growth Ce:GPS Crystals by Annealing in Air
}

\author{
Shusuke NISHIYAMA ${ }^{1, *}$, Sohan KAWAMURA ${ }^{1, \dagger}$, Junichi H KANEKO ${ }^{1}$, Mikio HIGUCHI ${ }^{1}$, Shunsuke UEDA ${ }^{2}$, \\ Kazuhisa KURASHIGE ${ }^{2}$, Hiroyuki ISHIBASHI ${ }^{2}$, Fumiyuki FUJITA ${ }^{1}$, Akira HOMMA ${ }^{1}$, Michihiro FURUSAKA ${ }^{1}$ \\ ${ }^{1}$ Graduate School of Engineering, Hokkaido University \\ N13, W8, Kita-ku, Sapporo, Hokkaido 060-8628 Japan \\ ${ }^{2}$ Hitachi Chemical Co.,Ltd., 1380-1, Tarazaki, Hitachinaka, Ibaraki 312-0003 Japan
}

\begin{abstract}
The change of scintillation property of the cerium doped gadolinium pyrosilicate $\mathrm{Ce}: \mathrm{Gd}_{2} \mathrm{Si}_{2} \mathrm{O}_{7}$ (Ce:GPS) single crystal by annealing in air was evaluated. The sample crystal was grown by using the floating zone method and the annealing was carried out at $1200{ }^{\circ} \mathrm{C}$ in 10 hours. The scintillation characteristics for gamma-rays, the photoluminescence emission and excitation spectra were compared between before and after the annealing process. It was found that the emission spectrum did not change by annealing except the overall intensity, while the excitation spectrum changed with increasing around $240 \mathrm{~nm}$ and $290 \mathrm{~nm}$ and the excitation band became wider by annealing in air. As a result, the scintillation efficiency for $662 \mathrm{keV}$ gamma-ray increased $6.4 \%$ by annealing in air.
\end{abstract}

KEYWORDS: annealing effect, gadollinium pyroscilicate, cerium-doped, radiation detectors, scintillators, floating zone method

\section{Introduction}

Present nuclear medical diagnosis instruments mainly use Tl:NaI, $\mathrm{Bi}_{4} \mathrm{Ge}_{3} \mathrm{O}_{12}$ (BGO), $\mathrm{Ce}: \mathrm{Gd}_{2} \mathrm{SiO}_{5} \quad(\mathrm{Ce}: \mathrm{GSO})$ scintillators ${ }^{1)-3)}$. For demand of improvement ability of these instruments, higher light output and faster decay time scintillator is needed, then, new scintillator materials such as $\mathrm{Ce}: \mathrm{Lu}_{2} \mathrm{SiO}_{5}(\mathrm{Ce}: \mathrm{LSO})^{4), 5)}, \mathrm{Ce}: \mathrm{Lu}_{2} \mathrm{Si}_{2} \mathrm{O}_{7}(\mathrm{Ce}: \mathrm{LPS})^{6)-8)}$, $\mathrm{Ce}: \mathrm{LaBr}_{3}{ }^{9), 10)}, \mathrm{Pr}^{2} \mathrm{Lu}_{3} \mathrm{Al}_{5} \mathrm{O}_{12}(\mathrm{Pr}: \mathrm{LuAG})^{11), 12)}$, and so on are developed.

As a part of a scintillator development for neutron detection, we fabricated $\mathrm{Ce}$ doped $\mathrm{Gd}_{2} \mathrm{Si}_{2} \mathrm{O}_{7}$ (Ce:GPS) powder based on the study of Yagi et al. ${ }^{13)}$, and it was found that the Ce:GPS has 1.2 times light output greater than Ce:GSO single crystal for alpha-particles of ${ }^{241} \mathrm{Am}^{14)}$. Later, we succeeded to fabricate a Ce:GPS single crystal by the floating zone method (FZ method). This crystal has good properties for scintillator, i.e., 2.5 times light output greater than Ce:GSO single crystal, $46 \mathrm{~ns}$ light decay time, and 6.0\% energy resolution for 662 $\mathrm{keV}$ gamma-rays ${ }^{15)}$. We achieved that 3 times light output greater than Ce:GSO and $5.1 \%$ energy resolution by optimizing the Ce concentration ${ }^{16)}$. Now we develop growing a large scale single crystal for gamma-ray measurement.

H. Feng et al. reported that annealing in air improve the light output of Ce:LPS grown under nitrogen atmosphere because of eliminating oxygen vacancies ${ }^{17}$. It is expected that the Ce:GPS crystal has many oxygen vacancies because the Ce:GPS crystal was also grown under nitrogen atmosphere.

In this paper, we evaluate the change of scintillation property of the Ce:GPS single crystal by annealing in air. The

\footnotetext{
*Corresponding author, E-mail: shu@eng.hokudai.ac.jp

${ }^{\dagger}$ Present address: NTT Photonics Laboratories, Nippon Telegraph and Telephone Corporation, 3-1, Morinosato Wakamiya, Atsugi, Kanagawa 2340198 Japan

(C)Atomic Energy Society of Japan
}

scintillation characteristics for gamma-rays, the photoluminescence emission and excitation spectra are compared between before and after the annealing process.

\section{Experimental Procedure}

\section{Sample preparation}

Powders of $\mathrm{Gd}_{2} \mathrm{O}_{3}$ (99.999\%), $\mathrm{SiO}_{2}(99.999 \%)$, and $\mathrm{CeO}_{2}$ $(99.99 \%)$ were used as starting materials. They were mixed at the composition of $\left(\mathrm{Gd}_{0.9} \mathrm{Ce}_{0.1}\right)_{2} \mathrm{Si}_{2} \mathrm{O}_{7}$ and put into a rubber bag. The bag was compressed by hydrostatic pressure of 70 $\mathrm{MPa}$ to form a $7 \mathrm{~mm}$ diameter rod. The rod was sintered at $1650{ }^{\circ} \mathrm{C}$ for 8 hours in air. The sintered rod was attached to the upper and lower shafts of an image furnace (FZ-T-10000H-III-TK; Crystal System Inc.), in which four $750 \mathrm{~W}$ halogen lamps were used. The growth was carried out in an $\mathrm{N}_{2}$ atmosphere with $2 \mathrm{~mm} / \mathrm{h}$ growth rate.

The single crystal part of the grown $10 \mathrm{~mol} \% \mathrm{Ce}$ doped GPS crystal was cut and its surfaces were polished. The dimension of the Ce:GPS sample was $(4 \times 3 \times 1) \mathrm{mm}^{3}$.

\section{Annealing process}

The annealing process was carried out with an electric furnace in air atmosphere by the following procedure. The sample temperature was raised linearly from room temperature to $1200{ }^{\circ} \mathrm{C}$ in 10 hours, and the temperature was kept during 10 hours, then, the sample was cooled to room temperature linearly in 10 hours.

\section{Scintillation characteristics measurement}

Scintillation characteristics of the sample were measured using a ${ }^{137} \mathrm{Cs} 662 \mathrm{keV}$ gamma-ray source. The sample was coupled with the window of a 2 inch diameter photomultiplier tube (H7195; Hamamatsu Photonics KK) using optical grease and covered with Teflon tape. Pulse height spectra were measured using a 113 Ortec scintillation preamplifier and a 672 Ortec spectroscopy amplifier with $0.5 \mu$ s shaping time. 


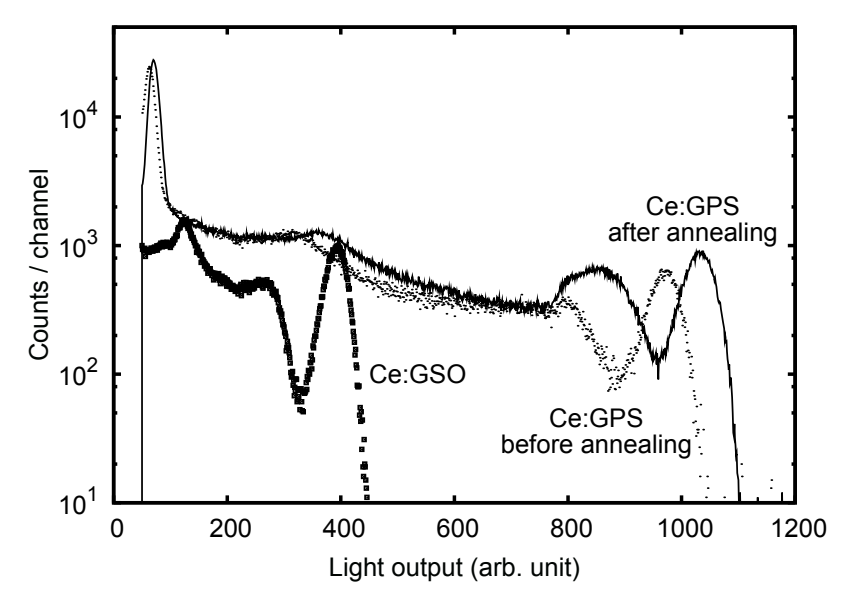

Fig. 1 Pulse height spectra of Ce $10 \mathrm{~mol} \%$ doped GPS single crystal before and after annealing for $662 \mathrm{keV}$ gammarays. Spectrum of Ce $0.5 \mathrm{~mol} \%$ doped GSO single crystal is also shown as a reference.

Pulse height spectra measurements of the Ce:GPS crystal sample were carried out before and after the annealing process. The pulse height spectrum of a $0.5 \mathrm{~mol} \% \mathrm{Ce}$ doped GSO single crystal was also measured in the same manner as a reference.

\section{Photoluminescence spectra measurement}

Photoluminescence spectra were measured at room temperature by a spectrometer (FP6500; JASCO Inc.). The excitation light wavelength were in range of $220-360 \mathrm{~nm}$ and the emission light spectra were measured at the wavelength between $350 \mathrm{~nm}$ and $450 \mathrm{~nm}$. Photoluminescence spectra were also measured before and after the annealing process.

\section{Results and Discussion}

\section{Scintillation characteristics for gamma-ray}

Figure 1 shows the pulse height spectra of the Ce:GPS sample before and after the annealing process for $662 \mathrm{keV}$ gamma-rays. The spectrum of the Ce:GSO is also shown.

The light output of Ce:GPS before annealing was 2.46 times greater than of the Ce:GSO. In our previous result, $\mathrm{Ce}$ 10 mol\% doped GPS showed 2.5 times light output greater than Ce:GSO ${ }^{15), 16)}$. Therefore, it was confirmed that the Ce:GPS sample preparation was carried out successfully.

Figure 1 also shows that the total energy peak of the Ce:GPS spectrum shifts to $6.4 \%$ lighter side by the annealing process. In a preliminary experiment, a Ce:GPS single crystal sample which had 2.3 times light output greater than Ce:GSO was improved to have 2.8 times greater light output by the annealing process, i.e., the light output was increased $22 \%$. These results show that the annealing process is effective to increase the light output.

\section{Photoluminescence spectrum}

The photoluminescence emission spectra under $240 \mathrm{~nm}$ light irradiation are shown in Fig. 2. The dashed line and solid

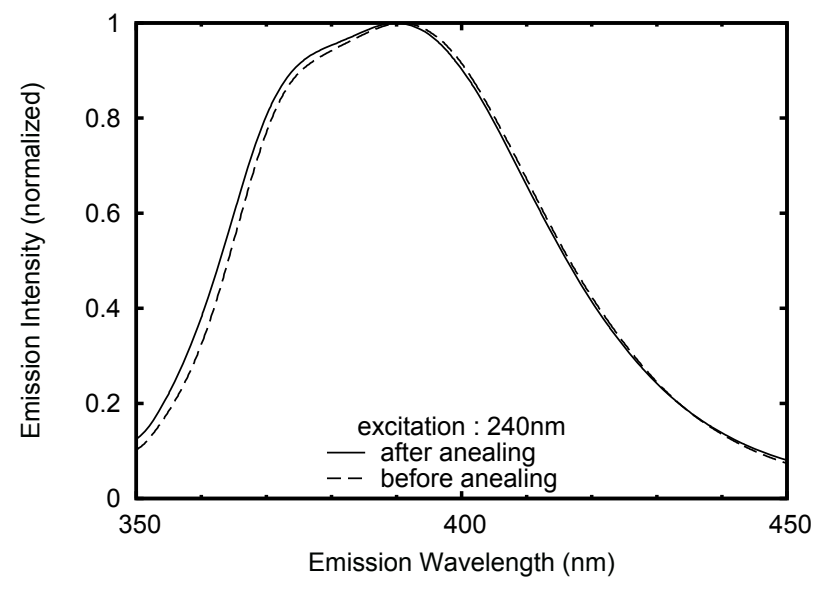

Fig. 2 Photoluminescence emission spectra of Ce:GPS before and after annealing. The excitation light wavelength is $240 \mathrm{~nm}$.

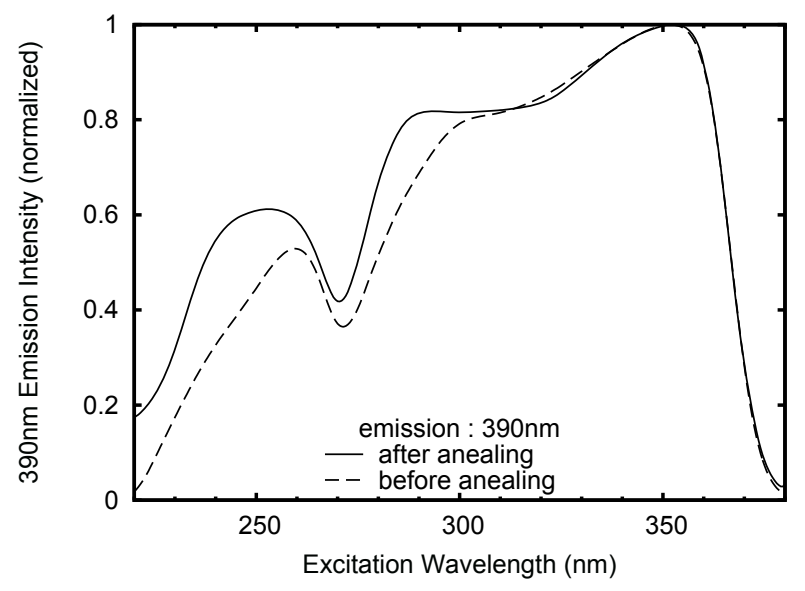

Fig. 3 Photoluminescence excitation spectra of Ce:GPS before and after annealing. The emission light wavelength is $390 \mathrm{~nm}$.

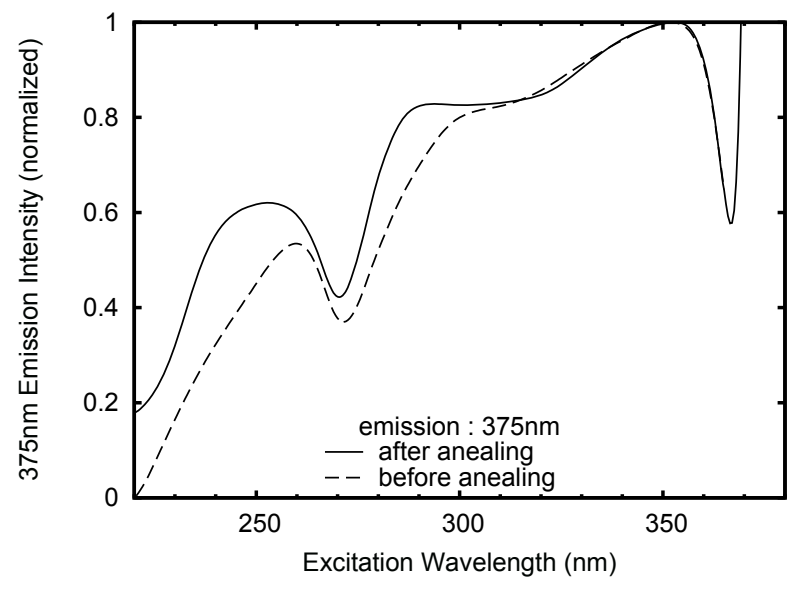

Fig. 4 Photoluminescence excitation spectra of Ce:GPS before and after annealing. The emission light wavelength is $375 \mathrm{~nm}$. 
line are the spectra of before and after the annealing process, respectively. These spectra are almost the same. It means that the light emission mechanism is not affected by the annealing process. This emission spectrum has two peaks at $375 \mathrm{~nm}$ and $390 \mathrm{~nm}$. These peaks correspond to the $5 \mathrm{~d}-4 \mathrm{f}$ transition in $\mathrm{Ce}^{3+}$ luminescent center ${ }^{15)}$.

In contrast, excitation spectrum of photoluminescence was changed by the annealing process. Fig. 3 and Fig. 4 are the excitation spectra measured at the wavelength of emission peaks, $390 \mathrm{~nm}$ and $375 \mathrm{~nm}$, respectively. In both cases, the excitation efficiency by the irradiation within $270-300 \mathrm{~nm}$ and below $260 \mathrm{~nm}$ is increased after the annealing process. In Ce:LPS crystal, high energy photons such as gamma-rays does not excite $\mathrm{Ce}^{3+}$ 4f electron directly but create electron-hole pairs, then the energy is transferd to the $\mathrm{Ce}^{3+}$ luminescent centers ${ }^{8)}$. Since Ce:GPS and Ce:LPS are both Ce dopnat-activated type scintillator, Ce:GPS also has the same scintillation mechanism. The wider and enhanced excitation band of Ce:GPS in UV region makes the energy tranfer more effective. Therefore, the annealing process causes the increase of light output as shown in Fig. 1.

\section{Conclusion}

The change of scintillation property of the Ce:GPS single crystal by annealing in air was studied. The emission spectrum did not change by the annealing process except the overall intensity, while the excitation spectrum changed with increasing around $240 \mathrm{~nm}$ and $290 \mathrm{~nm}$ and the excitation band became wider by annealing in air. As a result, the luminescence efficiency for $662 \mathrm{keV}$ gamma-ray increased 6.4\%. Although the annealing effect was relatively small for crystals that had high light output before annealing, the annealing process in air has a potential to equalize the luminescence efficiency of fabricated Ce:GPS crystals.

\section{Acknowledgment}

This study was supported by Research Fellowships of the Japan Society for Promotion of Science for Young Scientists and the Industrial Technology Research Grant Program in 2006 for the New Energy and Industrial Technology Development Organization (NEDO) of Japan.

\section{References}

1) C. W. E. van Eijk, "Inorganic scintillators in medical imaging", Phys. Med. Biol., 47, R85-R106 (2002).

2) Y. Utsu, S. Akiyama, "Growth and applications of $\mathrm{Gd}_{2} \mathrm{SiO}_{5}: \mathrm{Ce}$ Scintillators", J. Cryst. Growth, 109, 385-391 (1991).
3) O. H. Nestor, C. Y. Huang, "Bismuth Germanate: A High-Z Gamma-Ray and Charged Particle Detector", IEEE Trans. Nucl. Sci., 22[1], 68-71 (1992).

4) C. L. Melcher, J. S. Schweitzer, "A promising new scintillator: Cerium-doped lutetium oxyorthosilicate", Nucl. Instr. Meth. Phys. Res. A, A314, 212-214 (1992).

5) C. L. Melcher, J. S. Schweitzer, "Cerium-doped lutetium oxyorthosilicate: A fast, efficient new scintillator", IEEE Trans. Nucl. Sci., 39[4], 502-505 (1992).

6) D. Pauwels, N. Le Masson, B. Viana, et al., "A novel inorganic scintillator: $\mathrm{Lu}_{2} \mathrm{Si}_{2} \mathrm{O}_{7}: \mathrm{Ce}^{3+}$ (LPS)”, IEEE Trans. Nucl. Sci., 47[6], 1787-1790 (2000).

7) C. Yan, G. Zhao, Y. Hang, et al., "Comparison of cerium-doped $\mathrm{Lu}_{2} \mathrm{Si}_{2} \mathrm{O}_{7}$ and $\mathrm{Lu}_{2} \mathrm{SiO}_{5}$ scintillators", J. Cryst. Growth, 281, 411-415 (2005).

8) L. Pidol, A. Kahn-Harari, B. Viana, et al., "Scintillation properties of $\mathrm{Lu}_{2} \mathrm{Si}_{2} \mathrm{O}_{7}: \mathrm{Ce}^{3+}$, a fast and efficient scintillator crystal", J. Phys.: Condens. Matter, 15, 2091-2102 (2003).

9) W. M. Higgins, A. Churilov, E. van Loef, et al., "Crystal growth of large diameter $\mathrm{LaBr}_{3}: \mathrm{Ce}$ and $\mathrm{CeBr}_{3}$ ”, J. Cryst. Growth, 310, 2085-2089 (2008).

10) W. M. Higgins, J. Glodo, E. van Loef, et al., "Bridgman growth of $\mathrm{LaBr}_{3}: \mathrm{Ce}$ and $\mathrm{LaCl}_{3}: \mathrm{Ce}$ crystals for high-resolution gammaray spectrometers", J. Cryst. Growth, 287, 239-242 (2006).

11) H. Ogino, A. Yoshikawa, M. Niki, et al., "Scintillation characteristics of Pr-doped $\mathrm{Lu}_{3} \mathrm{Al}_{5} \mathrm{O}_{12}$ single crystals", J. Cryst. Growth, 292, 239-242 (2006).

12) A. Yoshikawa, M. Niki, G. Boulon, T. Fukuda, "Challenge and study for developing of novel single crystalline optical materials using micro-pulling-down method", Opt. Mater, 30, 6-10 (2007).

13) Y. Yagi, K. Susa, "Phase studies of the system $\mathrm{Gd}_{2} \mathrm{O}_{3}-\mathrm{Ce}_{2} \mathrm{O}_{3}$ $\mathrm{SiO}_{2}$ and their luminescence", Proc. of KEK-RCNP International School and Mini-Workshop for Scintillation Crystals, Tsukuba, Japan, Nov. 17-18, 2003, 4, 89-94 (2004).

14) S. Kawamura, J. H. Kaneko, M. Higuchi, et al., "Investigation of Ce-doped $\mathrm{Gd}_{2} \mathrm{Si}_{2} \mathrm{O}_{7}$ as a scintillator material", Nucl. Instr. Meth. Phys. Res. A, A583, 356-359 (2007).

15) S. Kawamura, J. H. Kaneko, M. Higuchi, et al., "Floating zone Growth and Scintillation Characteristics of Cerium-Doped Gadolinium Pyrosilicate Single Crystals", IEEE Trans. Nucl. Sci., 54[4], 1383-1386 (2007).

16) S. Kawamura, J. H. Kaneko, M. Higuchi, et al., "Scintillation Characteristics of Ce: $\mathrm{Gd}_{2} \mathrm{Si}_{2} \mathrm{O}_{7}$ (Ce 2.5-30 mol\%) Single Crystals Prepared by the Floating Zone Method", IEEE Trans. Nucl. Sci., 56[1], 328-330 (2009).

17) H. Feng, D. Ding, H. Li, et al. "Annealing effects on Czochralski grown $\mathrm{Lu}_{2} \mathrm{Si}_{2} \mathrm{O}_{7}: \mathrm{Ce}^{3+}$ crystals under different atmospheres", J. Appl. Phys., 103, 083109 (2008). 